\title{
Epigallocatechin-3-gallate ameliorates radiation-induced acute skin damage in breast cancer patients undergoing adjuvant radiotherapy
}

\author{
Wanqi Zhu' ${ }^{1}$, Li Jia ${ }^{3}$, Guanxuan Chen ${ }^{2}$, Hanxi Zhao ${ }^{1}$, Xiaorong Sun ${ }^{4}$, Xiangjiao \\ Meng ${ }^{1}$, Xianguang Zhao', Ligang Xing ${ }^{1}$, Jinming $\mathbf{Y u}^{1,2}$, Meizhu Zheng ${ }^{2}$ \\ ${ }^{1}$ Department of Radiation Oncology, Shandong Cancer Hospital Affiliated to Shandong University, Shandong Academy of \\ Medical Science, Jinan, Shandong, China \\ ${ }^{2}$ Shandong Key Laboratory of Radiation Oncology, Jinan, Shandong, China \\ ${ }^{3}$ Department of Radiation Oncology, Jinan Fourth People's Hospital, Jinan, Shandong, China \\ ${ }^{4}$ Department of Radiology, Shandong Cancer Hospital Affiliated to Shandong University, Shandong Academy of Medical \\ Science, Jinan, Shandong, China \\ Correspondence to: Hanxi Zhao, email: zhx87520052@163.com \\ Ligang Xing, email: xinglg@medmail.com.cn \\ Keywords: epigallocatechin-3-gallate, breast neoplasms, dermatitis, radiation \\ Received: December 21, $2015 \quad$ Accepted: May 04, $2016 \quad$ Published: May 20, 2016
}

\section{ABSTRACT}

There are few effective treatment options for radiation-induced dermatitis in breast cancer patients. We conducted a single-arm trial to tested the hypothesis that topical epigallocatechin-3-gallate (EGCG) is effective against radiationinduced dermatitis in breast cancer patients undergoing radiotherapy. Forty-nine patients participated in this study. The patients underwent mastectomy followed by adjuvant radiotherapy. Topical EGCG was applied daily, starting when grade I dermatitis appeared and ending two weeks after radiotherapy. The maximum dermatitis observed during the EGCG treatment was as follows: Grade 1 toxicity, $71.4 \%$ (35 patients); grade 2 toxicity, $28.6 \%$ (14 patients); there were no patients with grade 3 or 4 toxicity. The majority of the radiation-induced dermatitis was observed 1 week after the end of radiotherapy. EGCG reduced the pain in $85.7 \%$ of patients, burning-feeling in $89.8 \%$, itching in $87.8 \%$, pulling in $71.4 \%$, and tenderness in $79.6 \%$. These findings suggest topical EGCG may be an effective treatment for radiation-induced dermatitis and has acceptable toxicity.

\section{INTRODUCTION}

Despite technological advances, acute radiation skin toxicity (ARST) is the most common side effect of breast cancer radiotherapy, occurring in more than $90 \%$ of patients [1]. Complications such as pain, discomfort, irritation, itching, and burning-feeling may cause restriction in movement, unplanned treatment interruptions, and a decreased chance of getting an effective dose. These issues might reduce patients survival rates, as well as their quality of life (QOL) $[2,3]$.

Epigallocatechin-3-gallate (EGCG) facilitates the healing process in ultraviolet radiation-induced erythema in human skin [4]. Recent study has demonstrated that EGCG enhances viability of human skin cells and decreases apoptosis induced by X-ray irradiation [5]. In addition, recent studies from our laboratory have indicated that oral administration of EGCG protects esophageal epithelial cells from damage [6, 7].

Our recent phase I study has demonstrated that the topical administration of EGCG is safe, and that the recommended concentration is $660 \mu \mathrm{mol} / \mathrm{L}$ during skin radiation [8]. In this prospective study, we carried out a single-institution phase II trial to assess the effectiveness of EGCG as a topical agent for ARST, and to evaluate the radiation-induced dermatitis outcomes in women who underwent adjuvant radiotherapy (RT) for breast cancer. 


\section{MATERIALS AND METHODS}

\section{Patients}

Patients with modified radical mastectomy receiving external beam RT to chest wall were included in this study. Eligible patients were required to meet the following criteria: age $\geq 18$ years; ECOG PS 0 -1; no prior radiation to the thorax; adequate hematologic values (granulocytes $\geq 2,000 / \mathrm{ml}$, platelets $\geq 100,000 / \mathrm{ml}$, hemoglobin $>8 \mathrm{gm} / \mathrm{dl}$ ), hepatic function (bilirubin $<1.5$ normal), and renal values (creatinine clearance $>50 \mathrm{ml} / \mathrm{min}$ ). The exclusion criteria were as follows: positive deep margins; pregnancy or lactation; a known allergy or hypersensitivity to EGCG. The patients with large planning target volumes (PTV), sharp surface irregularities (a sudden change in the PTV depth), or an irregular contour (i.e. axillary folds, or inframammary folds), were also excluded. This study was approved by the Institutional Review and Ethical Committees and registered at ClinicalTrials.gov (NCT01481818). Informed consent was obtained from all patients.

\section{Radiotherapy}

Radiation treatment was delivered to the chest wall, including the surgical scar and regional lymph nodes, i.e., supraclavicular and infraclavicular nodes. Chest wall field arrangement included the area between the midsternal line medially, midaxillary line laterally, $2 \mathrm{~cm}$ below the contralateral inframammary fold inferiorly, and supraclavicular-axillary field superiorly. The field arrangement involved an anterior photon field against the supraclavicular and infraclavicular regions and an anterior electron field against the chest wall. All patients underwent simulation for verification of the irradiated fields and determination of chest-wall thicknesses. Additional boluses were used in the light of chest-wall thickness variation. The electron energy depended on the chest-wall thickness in the midplane (range, 6-12 MeV). RT was fractioned in 2 Gy five days a week up to 50 Gy [9].

\section{EGCG administration}

The treatment with EGCG solution was given to all patients undergoing RT immediately after grade I toxicity was documented (according to RTOG). The EGCG dose of $660 \mu \mathrm{mol} / \mathrm{L}$ (purity $\geq 95 \%$ by HPLC; from NINGBO HEP Biotech Co., Ltd) was chosen based on our previous study [8]. The solution was sprayed by the same investigator three times a day at $0.05 \mathrm{ml} / \mathrm{cm}^{2}$ to the whole radiation field for two weeks after radiation completion. The EGCG dose was calculated independently by two investigators; the average of the two measurements was used as the actual dose. EGCG solution was poured into sterilized throat medical sprayer, and uniformly sprayed on the skin from a distance of 10-20 $\mathrm{cm}$ from the skin. The skin folds, such as armpits required full stretch and exposure before spraying. Patients followed general good skin-care practices at the start of radiation therapy. They were also advised not to use deodorants, lotions, creams, perfumes, or any other products on the area during the course of radiation therapy.

\section{Toxicity evaluation}

EGCG was administered immediately when Grade 1 dermatitis was diagnosed. The dermatitis progression was recorded weekly until 2 weeks after the end of RT. Evaluation consisted of 1) provider-assessed toxicity assessment using a grading scale following the Radiation Therapy Oncology Group (RTOG) scoring system and 2) patients-reported symptoms measured using the Skin Toxicity Assessment Tool (STAT). The STAT is regarded as a valid and reliable skin-specific assessment tool [10]. The STAT scores range from 0 , representing no symptoms, to 5, representing the worst symptoms (pain, burning-feeling, itching, pulling and tenderness). All staff involved in the study received education on how to use the scale. The dermatitis was scored by two radiation oncologists with at least 8 years of experience. If the two scores were inconsistent, another senior doctor would evaluate the dermatitis. Toxicity was evaluated before and three hours after EGCG application, because the half-life of EGCG is about 3 hours [11]. Toxicity of EGCG was graded using the NCI Common Terminology Criteria for Adverse Events (CTCAE) version 3.0 [12].

\section{Statistical methods}

We calculated the estimated sample size using the perprotocol patient population based on the study by Fenig et al, reporting about $12-17 \%$ Grade 3-4 dermatitis probability in patients with $50 \mathrm{~Gy}$ skin radiation dose [13]. We reasoned that a probability of $17 \%$ would be unacceptably high, while a probability of $4 \%$ would be very promising from the clinical point of view. Assuming a significance level of 0.05 (2-sided), 49 assessable patients were needed to distinguish a Grade 3-4 radiation dermatitis rate of 4\% from an alternative rate of $17 \%$ with $80 \%$ power. The differences in the scores before, during and after treatment were tested using paired t-tests. The chi-square test was used to examine differences with categorical variables. SPSS (version 17.0; SPSS Inc., Chicago, IL) was used for statistical analyses. All statistical tests were two-sided. Values or $\mathrm{P}<0.05$ were considered significant.

\section{RESULTS}

The study started in August 2013, and ended in September 2014. Forty-nine eligible patients were 
included in the study. Characteristics of the forty-nine patients are listed in Table 1.

RT was delivered without treatment delays or interruptions to all 49 patients. Grade I dermatitis appeared in 17 patients during the second week of RT, in 24 patients during the third week, and in 8 patients during the fourth week. The mean duration of EGCG treatment was 4 weeks. The maximum radiationinduced skin toxicity observed during the course of EGCG treatment was as follows (Figure 1): Grade 1 toxicity, $71.4 \%$ (35 patients); grade 2 toxicity, $28.6 \%$ (14 patients); there were no patients with grade 3-4 dermatitis during the EGCG treatment. Importantly, 15 patients exhibited the personal minimum skin toxicity Grade 0 . There was a significant difference between the onset and the end of the study in RTOG scores $(\mathrm{N}=49$, $\mathrm{t}=4.38, \mathrm{p}<0.05)$. The RTOG score was not increased during RT in 35 out of 49 patients.

The patient-reported symptoms assessed by STAT were compared before and after the EGCG treatment (Figure 2). The mean scores of pain, burning-feeling, itching, pulling and tenderness were $0.86 \pm 0.82$, $1.41 \pm 0.70, \quad 1.92 \pm 0.93, \quad 0.94 \pm 0.72$ and $0.92 \pm 0.98$ at baseline, respectively. Rapid relief of toxicity (patient-reported symptom scores) was observed within 1 week of EGCG treatment in all patients (pain: $\mathrm{t}=5.229, \mathrm{p}<0.05$; burning-feeling: $\mathrm{t}=7.167, \mathrm{p}<0.05$; itching: $\mathrm{t}=9.478, \mathrm{p}<0.05$; pulling: $\mathrm{t}=2.14, \mathrm{p}<0.038$, and tenderness: $\mathrm{t}=4.499, \mathrm{p}<0.05$ ). Patient-reported symptom scores were also significantly decreased at the end of the study; pain, burning-feeling, itching, and tenderness scores were $\mathrm{t}=3.347 \mathrm{p}=0.004 ; \mathrm{t}=6.126$ $\mathrm{p}<0.05 ; \mathrm{t}=4.968 \mathrm{p}<0.05 ; \mathrm{t}=3.043 \mathrm{p}=0.008$, respectively. The regression of patient-reported symptoms related to ARST did not seem to depend on the onset time of EGCG. Our data indicate that EGCG has the ability to significantly and persistently control the symptoms of pain $(85.7 \%$ of patients), burning-feeling $(89.8 \%)$, itching $(87.8 \%)$, pulling $(71.4 \%)$, and tenderness $(79.6 \%)$. No reported acute toxicity was associated with EGCG.

\section{DISCUSSION}

In this phase II trial, EGCG was applied when patients developed Grade 1 dermatitis [14]. According to a previous study, about $12-17 \%$ of patients with 50 Gy skin radiation dose develop Grade 3-4 radiation dermatitis [13]. In our study, no Grade 3-4 dermatitis was found in patients who received the EGCG therapy, and most patients only suffered Grade 1 toxicity, even though they received the same radiation dose. Moreover, EGCG was well tolerated by patients, as we have previously demonstrated in phase I study [8]. The current study provides the clinical evidence for topical EGCG treatment to minimize radiation dermatitis.

Randomized controlled studies of skin care products compared with placebo had generally been negative in preventing or treating radiation dermatitis [15-19]. Recently, Miller et al has suggested that topical monetasone reduces $\geq$ Grade 3 radiationinduced dermatitis and alleviates the symptoms. However, there was no statistical difference between the mean maximum grades of radiation toxicity [20]. In addition, the side effects of monetasone, including periorificial dermatitis, skin atrophy, and mycotic infection also limited its application in clinic. Therefore, the evidence-based standard of care remained unclear.

A retrospective study demonstrated that topical green tea extracts helped to restore skin integrity in patients with Grade $\geq 2$ radiation-induced dermatitis receiving head and neck radiotherapy [21]. Our previous phase I trial also demonstrated that symptoms of radiationinduced dermatitis were alleviated in most patients receiving EGCG (24 patients, $40-660 \mu \mathrm{mol} / \mathrm{L})$, even during continued RT treatment [8]. Therefore, the efficacy of EGCG for treating radiation dermatitis warranted systematic studies.

EGCG has a role in scavenging superoxide anions, hydroxyl radicals, and hydrogen peroxide [22, 23]. EGCG protects deoxyribonucleic acid against radiationinduced damage through intercalating into DNA, binding to free radicals (FR), and repairing the FR-induced injury. EGCG can inhibit activity of proteasome, which is a key regulator of inflammation, thus inhibiting expression of pro-inflammatory cytokines, such as IL-1 $\beta$, IL-6, IL-8, and TNF $\alpha$ [24]. Moreover, tea polyphenols have been shown to suppress activity of the proteasome dependent transcription factor NF-B by inhibiting the p38 mitogenactivated protein kinase pathway and IкB kinases $[21$, $25,26]$. Therefore, the molecular mechanisms underlying the beneficial effects of EGCG in acute radiation-induced skin toxicity are complex and involve antibacterial and anti-inflammatory processes [21].

There are some limitations in the study. First, the dosimetry of the radiation region could not be ensured without three-dimensional planning radiotherapy. Therefore, future phase II randomized controlled trials should use techniques to improve the homogeneity of the planning target volumes. Second, the self-restore capacity of skin might also contribute to the positive result. The prospective randomized, place-controlled design is warranted in future studies.

Based on the clinical data from this trial, topical administration of EGCG solution appears to be an effective treatment for radiation-induced dermatitis in breast cancer patients after mastectomy. 


\begin{tabular}{|c|c|c|}
\hline & No. of Patients $(\mathrm{N}=49)$ & $\%$ \\
\hline \multicolumn{3}{|l|}{ Age(years) } \\
\hline Median & 45 & \\
\hline Range & $22-64$ & \\
\hline \multicolumn{3}{|l|}{ Smoking status } \\
\hline Yes & 14 & 28.6 \\
\hline No & 35 & 71.4 \\
\hline \multicolumn{3}{|l|}{ Performance status (ECOG) } \\
\hline 0 & 23 & 46.9 \\
\hline 1 & 26 & 53.1 \\
\hline \multicolumn{3}{|l|}{ T stage } \\
\hline $\mathrm{T} 1$ & 12 & 24.5 \\
\hline $\mathrm{T} 2$ & 27 & 55.1 \\
\hline $\mathrm{T} 3$ & 9 & 18.4 \\
\hline $\mathrm{T} 4$ & 1 & 2.0 \\
\hline \multicolumn{3}{|l|}{$\mathrm{N}$ stage } \\
\hline N0 & 1 & 2.0 \\
\hline N1 & 5 & 10.2 \\
\hline $\mathrm{N} 2$ & 38 & 77.6 \\
\hline N3 & 5 & 10.2 \\
\hline \multicolumn{3}{|l|}{ AJCC stage } \\
\hline IIIA & 44 & 89.8 \\
\hline IIIB & 1 & 2.0 \\
\hline IIIC & 4 & 8.2 \\
\hline \multicolumn{3}{|l|}{ Surgery to } \\
\hline Right breast & 23 & 46.9 \\
\hline Left breast & 26 & 53.1 \\
\hline \multicolumn{3}{|l|}{ Histology } \\
\hline Invasive ductal carcinoma & 44 & 89.8 \\
\hline Invasive lobular carcinoma & 5 & 10.2 \\
\hline
\end{tabular}




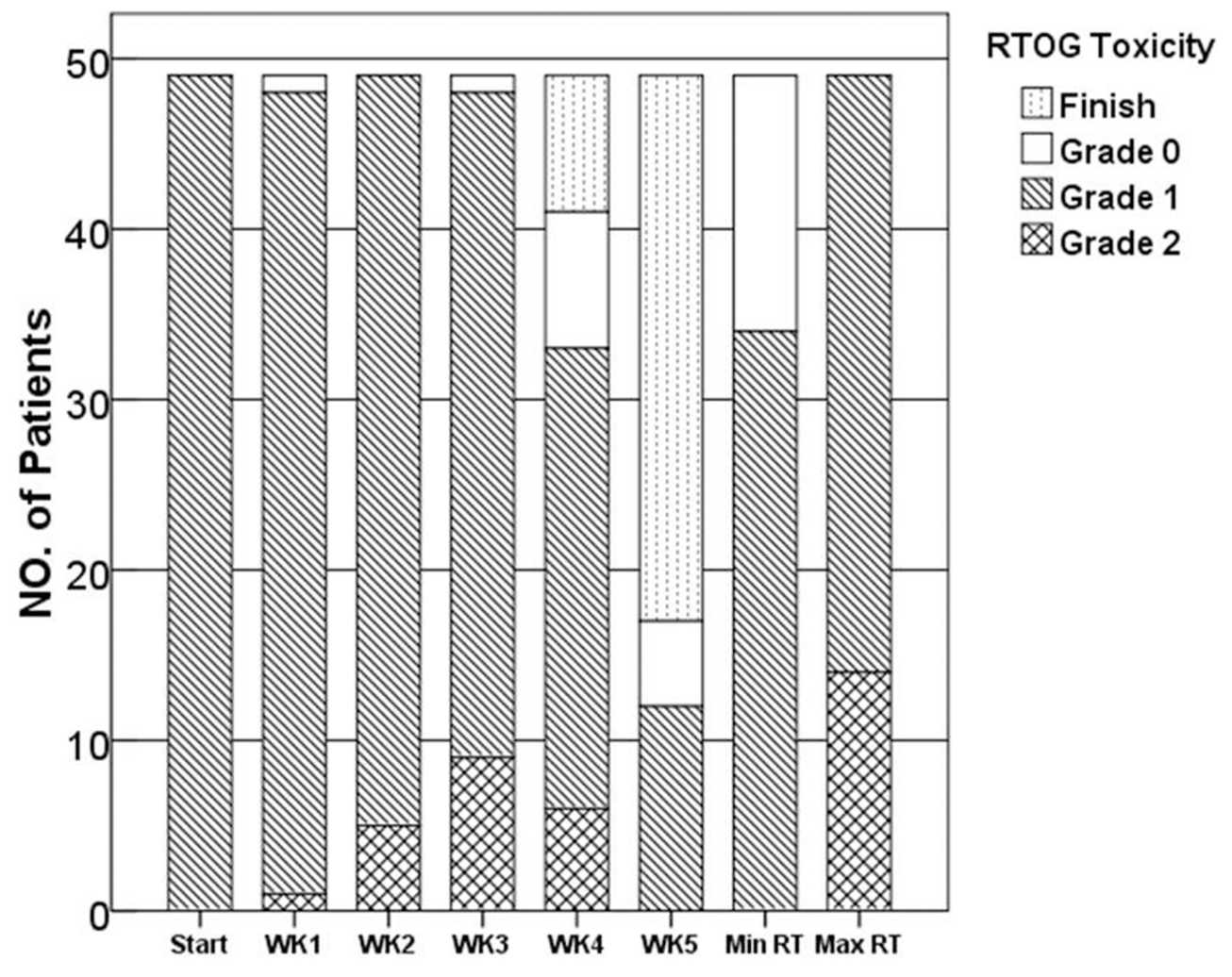

Figure 1: Skin reaction sores during EGCG treatment, as determined by the RTOG scoring system. Start=at the beginning of the EGCG therapy; WK1-5=after the first to fifth week of EGCG therapy; Max/Min RT=maximum/minus skin reaction scores during the course of EGCG therapy.
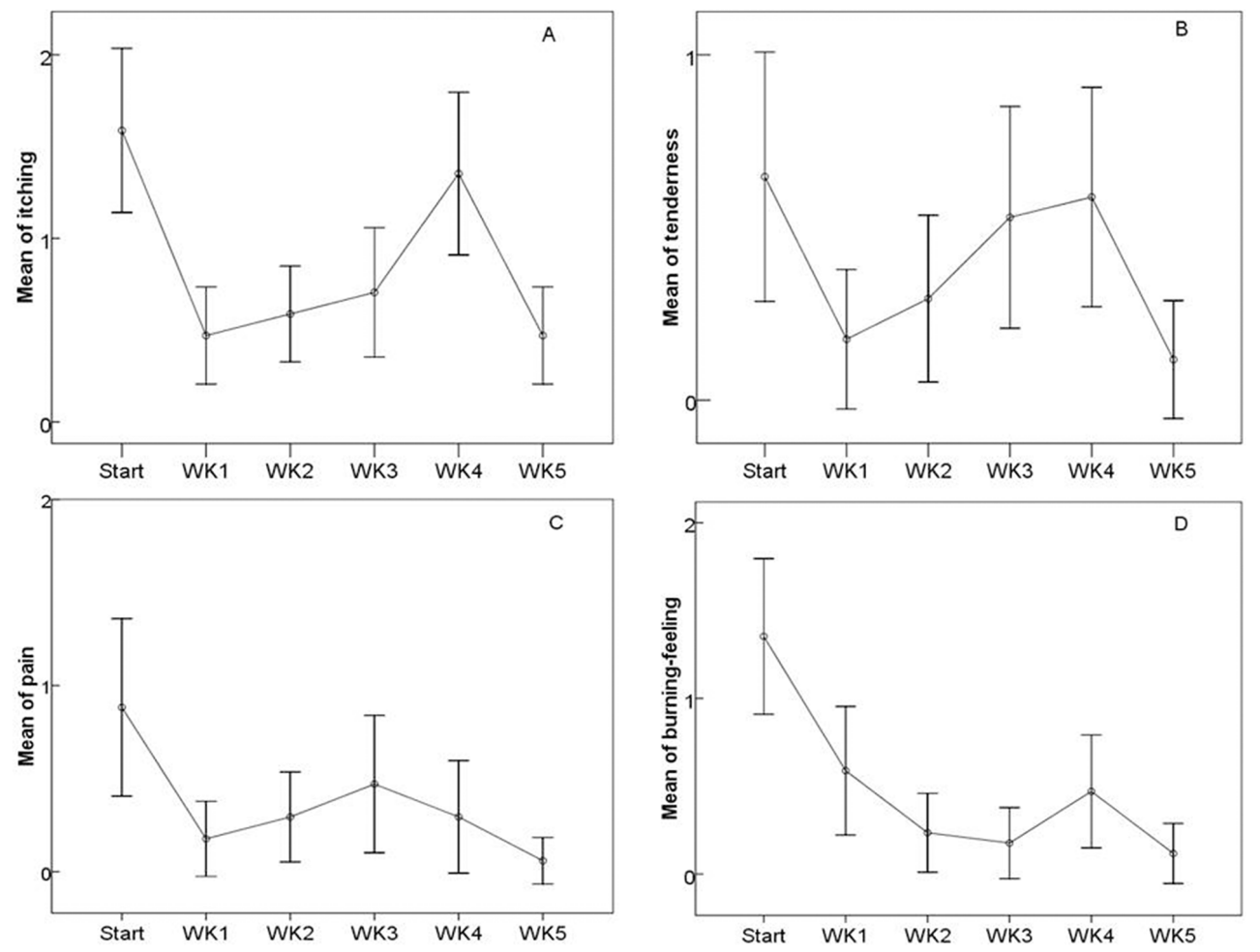

Figure 2: The changes of the patient-reported symptom scores during and after the treatments. A. Itching, B. Tenderness, C. Pain, D. Burning-feeling. 


\section{ACKNOWLEDGMENTS}

A part of this work was presented at the 2015 Annual Meeting of the American Society of Radiation Oncology (ASTRO), San Francisco, CA, USA.

\section{CONFLICTS OF INTEREST}

None.

\section{FUNDING}

This work was supported in part by grants from National Natural Science Foundation of China (81572970 and 81272502), and the grants from Shandong Provincial key scientific and technological project of China (2015GSF118132).

\section{REFERENCES}

1. Mulliez T, Veldeman L, van Greveling A, Speleers B, Sadeghi S, Berwouts D, Decoster F, Vercauteren T, De Gersem W, Van den Broecke R, De Neve W. Hypofractionated whole breast irradiation for patients with large breasts: a randomized trial comparing prone and supine positions. Radiother Oncol. 2013; 108:203-208.

2. Kirova YM, Fromantin I, De Rycke Y, Fourquet A, Morvan E, Padiglione S, Falcou MC, Campana F, Bollet MA. Can we decrease the skin reaction in breast cancer patients using hyaluronic acid during radiation therapy? Results of phase III randomised trial. Radiother Oncol. 2011; 100:205-209.

3. Chan RJ, Larsen E, Chan P. Re-examining the evidence in radiation dermatitis management literature: an overview and a critical appraisal of systematic reviews. Int J Radiat Oncol Biol Phys. 2012; 84:e357-362.

4. Scalia S, Marchetti N, Bianchi A. Comparative evaluation of different co-antioxidants on the photochemical- and functional-stability of epigallocatechin-3-gallate in topical creams exposed to simulated sunlight. Molecules. 2013; 18:574-587.

5. Zhu W, Xu J, Ge Y, Cao H, Ge X, Luo J, Xue J, Yang H, Zhang S, Cao J. Epigallocatechin-3-gallate (EGCG) protects skin cells from ionizing radiation via heme oxygenase-1 (HO-1) overexpression. Radiat Res. 2014; 55:1056-1065.

6. Zhao H, Zhu W, Xie P, Li H, Zhang X, Sun X, Yu J, Xing L. A phase I study of concurrent chemotherapy and thoracic radiotherapy with oral epigallocatechin-3-gallate protection in patients with locally advanced stage III non-small-cell lung cancer. Radiother Oncol. 2014; 110:132-136.

7. Zhao H, Xie P, Li X, Zhu W, Sun X, Sun X, Chen X, Xing $\mathrm{L}, \mathrm{Yu}$ J. A prospective phase II trial of EGCG in treatment of acute radiation-induced esophagitis for stage III lung cancer. Radiother Oncol. 2015; 114:351-356.
8. Zhao H, Zhu W, Jia L, Sun X, Chen G, Zhao X, Li X, Meng X, Kong L, Xing L, Yu J. Phase I Study of topical Epigallocatechin-3-gallate (EGCG) in patients with breast cancer receiving adjuvant radiotherapy. Br J Radiol. 2016; 89:20150665.

9. Gez E, Assaf N, Bar-Deroma R, Rosenblatt E, Kuten A. Postmastectomy electron-beam chest-wall irradiation in women with breast cancer. Int J Radiat Oncol Biol Phys. 2004; 60:1190-1194.

10. Neben-Wittich MA, Atherton PJ, Schwartz DJ, Sloan JA, Griffin PC, Deming RL, Anders JC, Loprinzi CL, Burger KN, Martenson JA, Miller RC. Comparison of providerassessed and patient-reported outcome measures of acute skin toxicity during a Phase III trial of mometasone cream versus placebo during breast radiotherapy: the North Central Cancer Treatment Group (N06C4). Int J Radiat Oncol Biol Phys. 2011; 81:397-402.

11. Kerksick CM, Roberts MD, Dalbo VJ, Kreider RB, Willoughby DS. Changes in skeletal muscle proteolytic gene expression after prophylactic supplementation of EGCG and NAC and eccentric damage. Food Chem Toxicol. 2013; 61:47-52.

12. National Cancer Institute. Common Terminology Criteria for Adverse Events (CTCAE) v3.0. http://ctep.cancer.gov/ protocolDevelopment/electronic_applications/docs/ctcaev3. pdf.

13. Fenig E, Brenner B, Katz A, Sulkes J, Lapidot M, Schachter J, Malik H, Sulkes A, Gutman H. Topical Biafine and lipiderm for the prevention of radiation dermatitis: a randomized prospective trial. Oncol Rep. 2001:8:305-309.

14. Elliott EA, Wright JR, Swann RS, Wright JR, Swann RS, Nguyen-Tân F, Takita C, Bucci MK, Garden AS, Kim H, Hug EB, Ryu J, Greenberg M, Saxton JP, Ang K. Phase III Trial of an emulsion containing trolamine for the prevention of radiation dermatitis in patients with advanced squamous cell carcinoma of the head and neck: results of Radiation Therapy Oncology Group Trial 99-13. J Clin Oncol. 2006; 24:2092-2097.

15. Ulff E, Maroti M, Serup J, Falkmer U. A potent steroid cream is superior to emollients in reducing acute radiation dermatitis in breast cancer patients treated with adjuvant radiotherapy. A randomised study of betamethasone versus two moisturizing creams. Radiother Oncol. 2013; 108:287-292.

16. Rollmann DC, Novotny PJ, Petersen IA, Garces YI, Bauer HJ, Yan ES, Wahner-Roedler D, Vincent A, Sloan JA, Issa Laack NN. Double-blind, placebo-controlled pilot study of processed ultra emu oil versus placebo in the prevention of radiation dermatitis. Int J Radiat Oncol Biol Phys. 2015; 92:650-658.

17. Lewis L, Carson S, Bydder S, Athifa M, Williams AM, Bremner A. Evaluating the effects of aluminum-containing and non-aluminum containing deodorants on axillary skin toxicity during radiation therapy for breast cancer: a 
3-armed randomized controlled trial. Int J Radiat Oncol Biol Phys. 2014; 90:765-771.

18. Chan RJ, Mann J, Tripcony L, Keller J, Cheuk R, Blades R, Keogh S, Poole C, Walsh C. Natural oil-based emulsion containing allantoin versus aqueous cream for managing radiation-induced skin reactions in patients with cancer: a phase 3, double-blind, randomized, controlled trial. Int J Radiat Oncol Biol Phys. 2014; 90:756-764.

19. Sharp L, Finnilä K, Johansson H, Abrahamsson M, Hatschek T, Bergenmar M. No differences between Calendula cream and aqueous cream in the prevention of acute radiation skin reactions-results from a randomised blinded trial. Eur J Oncol Nurs. 2013; 17: 429-435.

20. Miller RC, Schwartz DJ, Sloan JA, Grif n PC, Deming RL, Anders JC, Stoffel TJ, Haselow RE, Schaefer PL, Bearden JD 3rd, Atherton PJ, Loprinzi CL, Martenson JA. Mometasone furoate effect on acute skin toxicity in breast cancer patients receiving radiotherapy: a phase III doubleblind, randomized trial from the North Central Cancer Treatment Group N06C4. Int J Radiat Oncol Biol Phys. 2011; 79:1460-1466.

21. Pajonk F, Riedisser A, Henke M, McBride WH, Fiebich B. The effects of tea extracts on proinflammatory signaling. BMC Med. 2006; 4:28.
22. Richi B, Kale RK, Tiku AB. Radio-modulatory effects of green tea catechin EGCG on pBR322 plasmid DNA and murine splenocytes against gamma-radiation induced damage. Mutat Res. 2012; 747:62-70.

23. Mitrica R, Dumitru I, Ruta LL, Ofiteru AM, Farcasanu IC. The dual action of epigallocatechin gallate (EGCG), the main constituent of green tea, against the deleterious effects of visible light and singlet oxygen-generating conditions as seen in yeast cells. Molecules. 2012; 17:10355-10369.

24. Nam S, Smith DM, Dou QP. Ester bond-containing tea polyphenols potently inhibit proteasome activity in vitro and in vivo. J Biol Chem. 2001; 276:13322-13330.

25. Yang F, Oz HS, Barve S, de Villiers WJ, McClain CJ, Varilek GW. The green tea polyphenol (-)-epigallocatechin3-gallate blocks nuclear factor-kappa $\mathrm{B}$ activation by inhibiting I kappa B kinase activity in the intestinal epithelial cell line IEC-6. Mol Pharmacol. 2001; 60:528-533.

26. Pan MH, Lin-Shiau SY, Ho CT, Lin JH, Lin JK. Suppression of lipopolysaccharide-induced nuclear factor-kappaB activity by theaflavin-3,3'-digallate from black tea and other polyphenols through down-regulation of IkappaB kinase activity in macrophages. Biochem Pharmacol. 2000; 59:357-367. 